\title{
Factors influencing cost over-run in Indian construction projects
}

\author{
A. Cindrela Devi ${ }^{1, *}$, and K. Ananthanarayanan ${ }^{2}$ \\ ${ }^{1}$ Doctoral student, Civil Engineering Department, Indian Institute of Technology Madras, India \\ ${ }^{2}$ Professor, Civil Engineering Department, Indian Institute of Technology Madras, India
}

\begin{abstract}
Construction cost is the most important criteria of project success and hence the construction project performance is generally expressed in terms of cost and its variance from the budget. In spite of having extant literature, cost estimation methods, cost indices etc., construction projects rarely meet the budgeted cost. This research study focuses on the construction cost overrun and to identify the various factors that affects the construction cost performance. Based on an extensive literature review and input from industry experts, sixty eight factors that causes cost overrun were identified for investigation. Further, a structured questionnaire survey was conducted among the industry experts and the collected data has been analysed statistically. It is concluded that the factors namely scope creep, construction delays, rework and practise of awarding the contract to the lowest bidder are most significant factors for construction cost overrun in non-infrastructural Indian projects. The relative importance of the listed factors used to guide the project team in addressing the cost related risks involved in the projects. The findings are expected to bridge the gap in the current construction cost management practices.
\end{abstract}

\section{Introduction}

The construction project performance is generally expressed in terms of time and cost variance against its baseline. Out of the four fundamental constraints namely scope, cost, time and quality, cost performance is the most essential and common issue in the global construction industry [1]. It is important to measure the cost variance in construction to understand the performance of the project and thereby to understand financial risks involved in the project execution. The cost variance, resulting as project cost overrun is denoted as a negative impact on economy and the profitability. Several perspectives on cost overrun are available in extant literature and are proven valid. However, it is not adequately explained on why the cost overrun keeps occurring though sufficient knowledge on cost overrun has been largely shared.

The causes of inaccuracy in forecasts are different for different projects. The change of governance structures for forecasting the project development as an external factor also threat the project planning and execution. It was found that projects do not perform as forecasted,

${ }^{*}$ Corresponding author: $\underline{\text { cindreladevi@gmail.com }}$ 
in terms of costs: almost 9 out of 10 projects fall victim to significant cost overrun. The underlying causes of such inaccurate cost projections were investigated and summarized [2].

The research is proposed to improve current construction practices of determining the construction cost and controlling the cost as the project progresses. The aim is to propose a framework for managing the risk factors involved in cost performance of non-infrastructural construction projects and thereby developing construction cost assurance. This will be achieved on proper understanding of various risk factors which are the causes of cost overrun and understanding their impact on the project execution. To obtain this, the causes of cost overrun are to be identified and classified according to the different stages and progress of the project

\section{Motivation and need for study}

Cost overruns in construction projects around the world are very common. It represents the performance of the construction project and indicates the economic losses of the project. Cost overrun study was conducted across 20 nations in five continents and found that the average cost overrun for megascale projects could range from $20.4 \%$ to $44.7 \%$ [3]. Over the past 70 years, there have been no systematic improvements in cost overrun of the projects [4]. There is no established pattern for the occurrence of cost overrun [5]. In fact, cost overrun have the same magnitude as they had 30 years before, no improvements exists [6]. Hence the prediction of cost overrun, cause, its pattern, its frequency, impact on the progress are need to be explored to have a successful project completion.

The construction progress of projects are directly linked with the cash-flow and hence any unlikely performance of construction progress will directly hit the financial commitments. Traditionally, cost-benefit analysis is practiced for the investment purpose. It represents a most likely value of the project rather than the actual value. The input variables are carefully considered in 'what-if' scenarios or sensitivity tests for the analysis. However, the assessment of construction projects increasingly requires a greater understanding of its complexity on project progress and corresponding cash-flow. Hence, the number of 'whatif' scenario combinations were generated which makes the decision-making process more difficult. Therefore cost related risk factors are analysed in this research which will give strong base rather than having analysis on mythical or impractical situations.

Referring to the literature, it is obvious that there are number of causes of overruns and the impact on the construction costs are almost in similar patterns. In a study, eighty six explanatory factors had been listed out for the cost overrun [7]. It will be practically useful and have logical meaning for developing classification of causes based on their effect on the overruns of infrastructure projects [8]. However, in order to understand how and why cost overrun occur, listing down the causes of cost overrun can contribute minimum. Hence it is required to establish a framework for the cost performance of construction project in general and cost overrun in detail.

\section{Review of literature}

Cost is noted as one of the most important parameters and key driving force of project success among other considerations [9]. The measures such as total budgeted cost, cumulative budgeted cost, cumulative actual cost, cumulative earned value and estimated cost at completion are useful in evaluating the cost performance of the project [10,11]. Poor cost performance has been a major concern for all stakeholders in the construction project. Despite the large number of reported cases of poor performance, it seems that construction projects have increasingly experienced significant cost overruns on all projects ranging from the 
simplest to more complex projects such as nuclear plants, transportation systems and oil \& gas platforms [12]. As a result, many construction organizations have faced successive financial burdens, which often have led to insolvency and bankruptcy especially private construction sector.

Extant literature on cost performance is available for the government funding construction projects such as rail and road projects. However, non-infrastructural projects and profit oriented projects like residential, commercial constructions have not been studied on cost performance as the market is of huge competitors and the information on costing is being kept confidential. The challenge in the non-infrastructural construction project is sourcing of funds, cash-flow management, and completion of project on time. The performance of project is directly related to the cash-flow of the project, which in turn looped to the payment to the contractors that affects the construction progress [13].

The cost performance of the project highly rely on cost overrun, which is referred as an increase in the budget, cost or any growth in the cost. It has been calculated as the difference between the actual cost and the forecasted cost of the project [14]. If the percentage of cost overrun for the same project is compared by different planners may be different. The contradiction in the results of these studies is because of the point of reference based on which the cost overrun is measured. The reference point for estimating the cost overrun should be derived at the detailed planning stage where design, scope, specification and final cost are developed [15]. An alternative point of reference for determining cost overrun is the award of contract, which is the final negotiated and agreed price at the construction commencement $[16,17]$. The relationship between project size and cost overruns is notable as the larger the construction project is greater in the percentage cost overrun. The factors that contribute cost overrun are price escalation, poor design and implementation, inadequate financial plans, administrative uncertainty and the lack of coordination between enterprises [18]. Apart from these factors mentioned, the completion time or the duration of the project will also play a vital role.

Too many complexities in construction projects allow more probable cost overrun causes to emerge, and so risks and uncertainties increases. Hence, there might be greater variance in the cost and time schedule which leads to unsuccessful projects [19]. There are four types of explanations had been categorized for forecasting inaccuracy namely technical, economical, psychological and political explanations [20].

Two main causes of cost overruns because of the inaccuracies in the cost estimates are optimism bias and strategic misrepresentations [21]. Optimism bias can be explained as the cognitive disposition to evaluate future events in fairer light than they might actually be in reality [22]. The strategic misrepresentation is accounted for the systematic underestimation of the true costs and overestimation of benefits. The political and organizational pressures are very high for strategic misrepresentation as it is committed intentionally. Human judgments are generally optimistic due to overconfidence and incomplete information [23]. Thus people will underestimate the costs, and overestimate the benefits of the same action. This behaviour is called as planning fallacy. To get the true costs of the project and to have control over the cost overrun, better understanding is required on its pervasiveness of inaccuracy and risk in decision-making.

The other critical problem is project finance that obtains funds to bridge the time between making expenditures and obtaining revenues. Based on the concept design, the budget and the construction plan, the cash flow for a project can be estimated. Normally, this cash flow will involve expenditures in early periods. The challenge is covering this negative cash balance in the most beneficial or cost effective way. [24].

The above findings of various research have been integrated to develop a cost control mechanism with respect to non-infrastructural construction project in order to achieve project success (i.e) meeting the budgeted cost, scheduled time with the acceptable quality 


\section{Research objectives and methodology}

The research is proposed to improve current construction practices of determining the construction cost and controlling the cost of non-infrastructural project. The objectives of the research are as follows

- To identify the causes of cost overrun and their impact on project performance at various stages of the project

- To identify cost performance risk indicators and its frequency of occurrence in the project life cycle and thereby accurate cost can be predicted

The proposed methodology includes;

- Studying the literature on construction cost performance, cost overrun and its causes.

- Doing the case/ethnographical studies to observe the cost performance and to collect the data. Empirical evidence of cost performance risk factors, cost overrun and its causes were studied

- Questionnaire surveys and interviews were conducted with the stakeholders and professionals in Indian construction. The questionnaire was designed based on review of related literature and ethnographic studies. Statistical analysis was employed to discover the linkages between the cost overrun, risks involved and their impact on project performance.

- Identifying and categorizing the causes and impact of overrun in different stages of the project so as to develop a theoretical framework that portrays the occurrence of cost overrun at different stages of the project execution. It will demonstrate the relationships between types of cost overrun, its causes, and corresponding management approaches. Thus, the understanding of the costs and cost related risks, risks and risk related costs with respect to the project cost performance will be emphasized. The framework will sort the cost overrun causes and their occurrence with respect to the project progress. It will recognize and describe patterns of relationships among causes, overrun and corresponding management methodologies. This can be used as an indicator to predict the risk involved in the project execution at various stages and for the stakeholders.

\section{Questionnaire survey}

\subsection{Questionnaire design}

The questionnaire has been designed in such a way that it considers the objective of the study with the aim to answer the research questions. Based on an extensive literature review and input from industry experts, sixty eight factors that causes cost overrun were identified as shown in the Table.1. To validate the listed factors with respect to Indian construction sector, few discussions and feedback sessions were conducted with the industry professionals.

\subsection{Contents of the questionnaire}

The questionnaire has two sections comprising general information and the causes of cost overrun. The major causes of cost over-runs from the literature have been listed and the respondents were asked to state the frequency of causes of cost over-run happening in their past or current projects. The reply has been noted in terms of five point likert scale for each of the listed causes that was organised in the form of frequency scaling ( $1=$ never, $2=$ seldom, 3 = sometimes, $4=$ often , $5=$ always). The questionnaire was distributed to planning managers and cost consultants of 15 mega sized non-infrastructural projects like residential, commercial, hotel etc. The objective of the questionnaire survey is 
- To confirm the findings of cost over-run from the literature, in lieu with industry practices

- To understand the existence of cost overrun / risk factors in Indian construction (noninfrastructure) projects

- To establish the relative importance of the various factors responsible for cost overruns

- To understand the linkages between the causes of overrun

\subsection{Data Analysis}

In order to establish the relative importance of the various factors that are responsible for cost over-run, the score for each factor is calculated. This is done by summing up the scores given by all respondents. The relative importance weight is derived using the following equation.

$$
\text { Relative Importance Weight }(\mathrm{RIW})=\frac{\sum_{i=1}^{5} a_{i} \cdot n_{i}}{\sum_{j=1}^{N} x_{j}} \times 100
$$

where $\mathrm{i}$, is score of the factor ranging from 'never' to 'always' as shown below, $\mathrm{N}$ is total no of factors, $x_{j}$ is the sum of the jth factor, $\mathrm{j}$ is the factor from 1 to $\mathrm{N}, \mathrm{a}_{\mathrm{i}}$ is the weight expressing for the ith response, $n_{i}$ is the frequency of the ith response from all respondents

Using the equation (1), the Relative importance weight is calculated for the cost over-run factors describing for a response of 'never' $a_{1}=1$, for a response of 'seldom' $a_{2}=2$, for a response of 'sometimes' $\mathrm{a}_{3}=3$, for a response of 'often' $\mathrm{a}_{4}=4$, for a response of 'always' $\mathrm{a}_{5}=5$. The RIW is a useful measure of relative positioning of particular factor. Though this score does not represent the statistically significant measurement, it is a good indicator of occurrence of cost overrun in projects

Table 2. The causes of cost over-run with perceived ranks.

\begin{tabular}{|c|c|c|c|c|c|}
\hline S.No & Causes of overrun & RIW & S.No & Causes of overrun & RIW \\
\hline 1 & Increase in material prices & 1.77 & 35 & Changes in the specifications & 2.10 \\
\hline 2 & Inflation & 1.70 & 36 & Design error & 1.54 \\
\hline 3 & Increase in wages & 1.67 & 37 & High interest charged by the Bankers on loan & 1.17 \\
\hline 4 & Price fluctuations & 1.74 & 38 & Incomplete drawings & 1.90 \\
\hline 5 & Labour cost increased due to & 1.24 & 39 & Inadequate specifications & 1.67 \\
\hline 6 & Financial difficulties of & 0.90 & 40 & Waste on site & 1.80 \\
\hline 7 & slow or delayed payment of & 1.40 & 41 & Equipment availability and failure & 1.17 \\
\hline 8 & Market conditions & 1.64 & 42 & Delay in decision making & 1.84 \\
\hline 9 & Fluctuation in money & 1.14 & 43 & Poor financial control at site & 1.24 \\
\hline 10 & Deficiencies in cost estimate & 1.34 & 44 & Many works being done at the same time & 1.67 \\
\hline 11 & deficiencies in the & 1.14 & 45 & Lack of constructability & 1.04 \\
\hline 12 & Insurance problems & 0.74 & 46 & Complicated design & 1.34 \\
\hline 13 & Problems related to work & 1.00 & 47 & Changes in the scope of the project & 2.07 \\
\hline 14 & Problems related to workers' & 0.97 & 48 & Insufficient equipment and technology & 1.20 \\
\hline 15 & Additional works & 2.21 & 49 & Optimism bias & 1.07 \\
\hline 16 & Inaccurate quantity take-off & 1.24 & 50 & Fraudulent practices & 0.84 \\
\hline 17 & Lack of experience in project & 1.00 & 51 & Disputes on site & 1.47 \\
\hline 18 & Lack of communication & 1.60 & 52 & Owner interferences & 1.30 \\
\hline 19 & Lack of experience of project & 1.14 & 53 & Lack of experience of local regulations & 1.30 \\
\hline 20 & Contractor's poor site & 1.54 & 54 & Change of regulations by Govt & 1.60 \\
\hline 21 & Inadequate contractor & 1.30 & 55 & $\begin{array}{l}\text { Political complexities } \\
\end{array}$ & 1.57 \\
\hline 22 & Shortage of site workers & 1.84 & 56 & Practice of assigning the contract to the lowest & 2.04 \\
\hline 23 & Unrealistic contract duration & 1.40 & 57 & strategic misrepresentation & 1.14 \\
\hline 24 & Mistakes during construction & 1.50 & 58 & Change of Laws and regulatory framework & 1.54 \\
\hline 25 & Inaccurate site investigation & 1.24 & 59 & Unpredictable weather conditions & 1.90 \\
\hline 26 & Lack of coordination between & 1.90 & 60 & Unforeseen site conditions & 1.57 \\
\hline 27 & Rework & 2.00 & 61 & Deficiencies in the social structure & 1.04 \\
\hline 28 & Unexpected subsoil & 1.70 & 62 & Heritage materials being discovered & 0.63 \\
\hline 29 & poor technical performance & 1.10 & 63 & Construction delays & 2.34 \\
\hline 30 & Design changes & 2.14 & 64 & Inaccurate estimates & 1.27 \\
\hline 31 & Incorrect planning and & 1.80 & 65 & Cash flow and financial difficulties faced by & 1.94 \\
\hline 32 & delay in material procurement & 1.84 & 66 & Insufficient time to prepare estimate & 1.00 \\
\hline 33 & Delays in design & 1.70 & 67 & Shortage of materials & 1.37 \\
\hline 34 & Late delivery of materials and & 1.50 & 68 & Lack of experience in contract. & 1.24 \\
\hline
\end{tabular}


In order to measure the degree of agreement among the respondents on the construction cost over-run on the cost performance of the projects, two hypotheses were developed, as follows:.

- Null hypothesis $\mathrm{H}_{0}$ : Disagreement among respondents in occurrence of the cost overrun in the construction projects

- Alternative Hypothesis $\mathrm{H}_{1}$ : Agreement among respondents in occurrence of the cost overrun in the construction projects

If there is significant agreement among respondents on the cost overrun issues on construction projects, the contribution made in this research are highly relevant in achieving the targeted cost performance and thereby achieving success in the project. To test the commonality among the respondents, Kendall's coefficient of concordance (W) is considered as relevant for the study and with respect to the attribute ranking. Since the ranks have more ties in the factors listed, the Kendall's coefficient has been calculated considering the ties between the factors using the below formula.

$$
\text { Kendall's Coefficient of Concordance }(\mathrm{W})=\frac{12 s^{2}-3 m^{2} k(k+1)^{2}}{m^{2}\left(k^{3}-k\right)-m T}
$$

where $\mathrm{k}$ is total no of factors, $\mathrm{m}$ is no of respondents, $\mathrm{T}$ is ties in the scores, $\mathrm{S}$ is sum of scores. The Calculated $\mathrm{W}$ value is 0.56 . As the number of factors $(\mathrm{N})$ is too large to check on the critical values of Kendall's, chi-square approximation of sampling distribution of $\mathrm{W}$ is calculated with the below equation.

$$
\text { Chi square } X^{2}=k(m-1) W
$$

The calculate Chi-square value is 567.72 is greater than the critical value of chi-square from the table for the degree of freedom $=67$ and significant level $=0.05$. Hence, the null hypothesis is rejected and alternative hypothesis is accepted. Therefore, it is concluded that there is significant degree of agreement among the respondents for the occurrence of cost overrun in the non-infrastructural Indian construction projects.

\subsection{Survey results and conclusions}

A summary of all the factors causing the cost overrun is been listed and as seen in Table 2, the overall ranking reveals that various factors influence the cost performance in projects. The most significant factors that cause construction cost overrun are shown in Table 3 based on the Eq (1) with the appropriate occurrence on the project life cycle and classified as internal and external issues

Table 3. Most significant factors of causes of cost over-run.

\begin{tabular}{|c|c|c|}
\hline Project stage & Internal Issues & External Issues \\
\hline Pre-planning & Financial difficulties & Delay in regulatory approvals \\
\hline $\begin{array}{c}\text { Planning \& } \\
\text { Design }\end{array}$ & $\begin{array}{c}\text { Scope creep } \\
\text { Design / specification changes } \\
\text { Poor selection of contractors } \\
\text { Ineffective procurement planning }\end{array}$ & $\begin{array}{c}\text { Changes of laws and regulatory } \\
\text { framework } \\
\text { Political complexities } \\
\text { Unforeseen site conditions }\end{array}$ \\
\hline $\begin{array}{c}\text { Execution and } \\
\text { Monitoring }\end{array}$ & $\begin{array}{c}\text { Rework } \\
\text { Construction Delays } \\
\end{array}$ & $\begin{array}{c}\text { Inflation / price fluctuations } \\
\text { Delay in decision making } \\
\text { Contractual disputes }\end{array}$ \\
\hline
\end{tabular}

Considering all the identified factors along with their potential occurrence in the project life cycle, Fig.1 shows the percentage of frequency of cost overrun in the project 
performance. The study says that the cost over-run occurs in detailed design stage about $68 \%$ as often and always and about $37 \%$ at execution stage of the project.

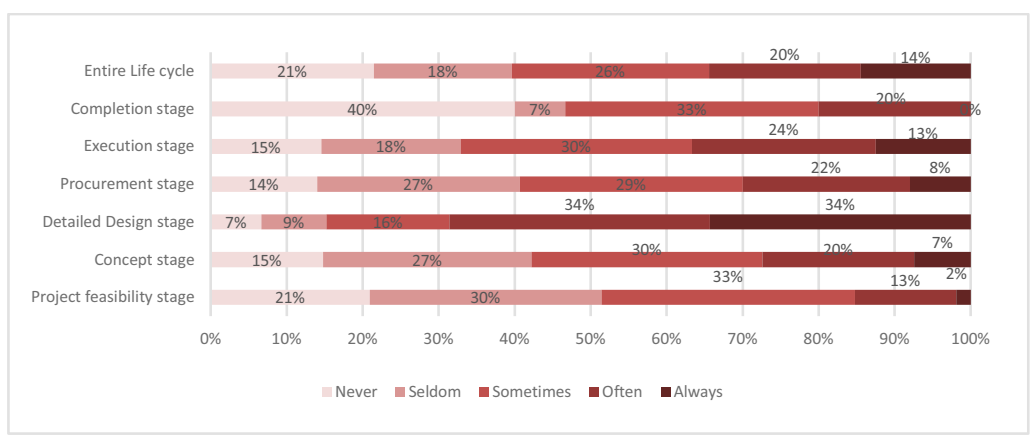

Fig. 1. Cost overrun occurs during the phases of construction.

This study has been focused on assessing cost overrun problems and their causative factors in the non-infrastructural Indian construction projects. The structured questionnaire was used to acquire information on the relative importance of cost overrun factors. A descriptive statistical analysis was carried out and the following findings were discovered

- Cost overrun is a major issue in project performance and agreed by $97 \%$ of the respondents

- The cost baseline is been fixed at different stages of project for various projects and is been revised many times in the project

- The most significant cause of cost overrun includes scope creep, construction delays, rework and practise of awarding the contract to the lowest bidder

- the changes in design and specifications, changes in scope, additional works, design errors, incomplete design, delay in design delivery reflects in delayed construction, excess contractual claims, disputes at site and poor project management

- price fluctuations, inflation, increase in wages and material prices could be related to the contractual clauses to avoid cost overrun during execution of the project

- poor coordination at site, poor communication are the internal factors that reflects the delay in construction and contractual disputes

- proper procurement strategy to be executed for awarding the contracts / consultants / suppliers as the result shown as the practice of boarding lowest bidder reflect cost overrun and extra claims at the project closure

- delayed construction contributes poor project performance in terms of cost also. It results in poor scheduling of project, complexity of constructions not considered in scheduling of the project. Hence appropriate risk analysis tool and scheduling methods to be used to mitigate.

- the internal factors mentioned in the Table 3 can be mitigated through proper training to the planning team / managers

- the external factors mentioned in the Table 3 can be mitigated through appropriate risk analysis technique before project inception

\section{Recommendation}

The objective of this study has been to investigate the statistical relationship between the cost overrun factors and the causes. The data has revealed that the most significant cost overrun factors that occur in various stages of the project. With overwhelming statistical significance, it is evident that there is significant agreement among the respondents on the occurrence of cost overrun in the non-infrastructural Indian projects. From the findings of this study, project 
managers can effectively mitigate risks of significant overruns by executing corrective and preventive action plans. Few other recommendations for mitigating the cost over-run risks are as follows:

- Decision making is important in all stages on project life cycle cost

- To include cost specific (eg escalation) clauses as a part of contract agreement

- To develop cost effective project planning \& design by minimizing waste, having fixed price contract for key services, procuring critical and volatile materials early, having corporate alliance with key vendors / contractors and having long term supply agreements / item rate contracts

- Grouping of causes -- with respect to the responsibilities of stakeholders rather than explaining reasons for the overruns

- Identifying where the cost overrun could have happened in the project timeline against project progress and how could have been eradicated

\section{References}

1. Donald Towey, Cost Management of Construction Projects (2013)

2. Flyvbjerg, Bent, Mette K. Skamris Holm, and Søren L. Buhl. J. American Planning Asso, $68,3,279-295$ (2002)

3. Flyvbjerg, B., N. Bruzelius and W. Rothengatter. Megaprojects and Risk: An Anatomy of Ambition (2003a).

4. Bruzelius, N., B. Flyvbjerg, W. Rothengatter. Transport Policy, 9, 2, 143-154 (2002).

5. Lundman P. Cost Management for Underground Infrastructure Projects: A Case Studyon Cost Increase and its Causes, Luleå University of Technology, report. (2011)

6. Flyvbjerg, Bent, Mette K. Skamris Holm, and Søren L. Buhl. Transport Reviews, 24, 1, 3-18 (2004)

7. Memon, A. H., Rahman, I. A. \& Aziz, A. A. A. Int. J. Real Estate Studies, 7 (2012)

8. Cantarelli C, Flyvbjerg B, Molin E J E, \& Van Wee B. European J. Trans. and Infra Research, 10, 1, 5-18 (2010)

9. Azhar, N., Rizwan U. Farooqui \& Ahmed, S.M. Advancing and Integrating Construction Education, Research \& Practice, 499-508 (2008).

10. Gido, J. and Clements, J. P. Successful Project Management, 2nd edition. (2003)

11. Suqrat Babar, Muhammad Thaheem, J. Const. Engg. Man. 143, 3 (2017)

12. Al-Bahar, J.F. and Crandall, K.C. J. Const. Engg. Man., 116, 3, 533- 546 (1990).

13. Wenhua Hou. J. Convergence Information Technology, 7, 18, 29-35 (2013)

14. Merrow A H, Rahman I A \& Azis A. Int J. Sustainable Construction Engineering \& Technology, 2, 1, 57-71 (2011)

15. James Odeck. Transport policy, 11, 1, 43-53 (2004)

16. Ganuza, J. J.of Industrial Eco, 55, 4, 633-660. (2007)

17. Love P E D, Wang X, Sing C \& Tiong R. J. Const. Engg. Man. 139, 321-330 (2013)

18. Cantarelli C C, Molin E J E, van Wee B \& Flyvbjerg, B. Transport Policy, 22, 49-56 . (2012)

19. Abdelgawad, M., Fayek, A.R. J. Const. Engg. Man. 137, 294-302 (2010).

20. Flyvbjerg, Bent, Mette K. Skamris Holm, and Søren L. Buhl. J.American Planning Association, 71, 2, 131-146 (2005)

21. Flyvbjerg, Bent and Cowi. Procedures for Dealing with Optimism Bias in Transport Planning, Guidance Document, UK Department for Transport. (2004)

22. Lovallo, Dan and Daniel Kahneman. Delusions of Success: How Optimism Undermines Executives' Decisions, Harvard Business Review, 7, 56-63. (2003)

23. Kahneman, D. and Tversky, A. Econometrica, 47, 313-327. (1979)

24. Jing Du, Byung-Cheol Kim, Dong Zhao, J. Const. Engg. Man. 142, 6 (2016) 